\title{
Delinquency and Icelandic Adolescents' Viewing of Television Violence
}

\author{
GuĐbJörg Hildur Kolbeins
}

During the 1990s, discussion about the causes of juvenile delinquency and aggression among children and adolescents became more prevalent in Iceland. Not surprisingly, people blamed the amount of violence in entertainment media for the apparent increase in the juvenile delinquency rate.

For the past four decades or so, a plethora of studies has been conducted on the relationship between aggression and filmed violence. The vast majority of the research has found a positive relationship between viewing of violence and aggressive behavior, no matter whether the studies were done in a laboratory setting (for ex. Bandura et al., 1963) or as longitudinal research (for ex. Huesmann, 1986; Eron \& Huesmann, 1986).

After doing a meta-analysis on 217 studies, dating between 1957 and 1990, Paik and Comstock reported that the overall correlation between viewing violence and antisocial behavior is . 31. Paik and Comstock argue that "this $10 \%$ increase in success rate, or 10 viewers out of 100 being affected by television violence, cannot be dismissed as an insignificant effect" (Paik \& Comstock, 1994: 535). However, it should be noted that when the survey design has been used to investigate the relationship between criminal violence and violence viewing, the correlation is only .06 and thus accounting for only $0.4 \%$ of the variance (Paik \& Comstock, 1994).

Although the tendency has been to assume that television violence is the antecedent to aggressive behavior, i.e. the cause of the behavior, a number of studies has found that although we have a correlation between violence viewing and aggressive/antisocial behavior, aggressive people may actually be seeking out violent material (Bryant, 1989; Gunter, 1983; Black \& Bevan, 1992).

When the research, which is reported in this paper, was conducted, the relationship between television viewing and aggressive behavior among Icelandic adolescents was an unknown territory, i.e. no study had attempted to replicate in Iceland the findings from studies elsewhere in the world.

More specifically, the present study attempted to answer the following two questions: Does viewing of violent television shows increase the aggressiveness of Icelandic adolescents? Does viewing violent television shows increase juvenile delinquency, other than aggression, among Icelandic adolescents?

It was expected that: 
1. There will be a positive relationship between the adolescents' viewing of television violence and their level of aggressiveness.

2. There will be a positive relationship between the adolescents' viewing of television violence and their delinquent behavior.

At the time of the present study, Icelanders had lived with television for just over three decades, and in a multi-channel environment for 12 years. Hence, the oldest adolescents, who participated in this study, were still pre-schoolers when broadcasting was deregulated, and many of the youngest subjects had no recollection of a single-channel home.

Considering the dramatic changes in the availability of channels and increased air time in Iceland, one might say that these adolescents belong to the first generation of viewers who were raised in a similar television environment to their counterparts' in the United States and in other European countries. Thus, keeping in mind the number of studies which have found a relationship between viewing of violence and aggressive behavior, one might expect the results of the present study to be consistent with these other studies and to find a significant association between viewing of television violence and aggression and delinquency among Icelandic adolescents.

\section{Sample and Procedure}

The sample for the present study was recruited from ten public schools in the Reykjavíkmetropolitan area in Iceland. With the exception of two of the schools, four classes were randomly selected from each school, i.e. one in 7 th grade, one in 8 th grade, one in 9 th grade and finally one in 10th grade

The sample (674 individuals) ranged in age from 11 to 16 . Girls were $54.2 \%$ of the sample (365) girls and boys $45.8 \%$ (309).

All of the questionnaires were administered by the students' teachers who had received written instructions from the researcher. According to Thóroddur Bjarnason (1995), this method of administering the questionnaires does not affect the validity or the reliability of the study. It has even turned out to be better sometimes to have a familiar figure (the teacher) administer the questionnaires instead of an outsider (the researcher or his research assistants). The students had 40 minutes, one class hour, to answer all of the questions.

\section{Parental Education and Income}

To get some crude measure of parental education and SES status, macro data on the percentage of college educated people in the adolescents' school districts and the average monthly family income in the school districts were obtained from the Social Sciences Research Institute at the University of Iceland.

But what does the percentage of college educated people in the adolescent's school district really tell us? In some cases it tells us something about the adolescent's parents, but it also tells us something about the adolescent's neighborhood and his/her friends as friendships are usually formed with those who have similar backgrounds as we do. Since children in Iceland usually attend school in their own neighborhoods and within a fiveor a ten-minute walking distance from their homes, their out-of-class friends are usually their class mates. Like the proverb goes: "Birds of feather flock together". Thus, the macro data cannot simply be taken at face value. It's indirectly telling us a lot more than 
just what the average family income is or what the percentage of college graduates in the school district is.

\section{Total Viewing of Television}

Two questions tapped the frequency of television viewing. More specifically the first question asked: "From Monday to Friday, how many hours a day do you usually watch television? " The other question asked: "How many hours a day do you usually watch television on Saturdays and Sundays?"

The options were the same for both questions, i.e. one hour or less (1), one to two hours (2), two to three hours (3), three to four hours (4), four to five hours (5), five to six hours (6), six to eight hours (7) and eight hours or more (8).

Those two questions were then weighted proportionally (the score for Monday through Friday was multiplied by five and added to the score for Saturdays and Sundays which was multiplied by two) and combined to create one variable that could be a reliable measurement of total television viewing.

\section{Viewing of Genres}

Since so many homes in Iceland have now access to satellite television and foreign channels, it wasn't thought to be realistic to present the sample with lists of programs that are only broadcast on the four Icelandic channels. Instead, it was felt that it would work better to have the subjects rate their frequency of viewing of specific genres on a Likerttype nine-point scale. The problem with doing that, of course, is that one is leaving it up to each individual to decide what our measures or scales actually mean. Does "6", for example, mean once a week or does it mean three times a week? On the other hand, one could argue that the individual's definition is more important and is more meaningful than the researcher's because in terms of effects, it's the individual's definition and experience of the event that really matters but not necessarily how often it happened.

The question on viewing of genre asked: "How often do you watch the following material on television?" The students were then asked, for example, to circle 9 if they watched frequently or to circle 1 if they never watched that specific genre.

The question included the following genres: a) situation comedies, b) cartoons, c) children and family programs, d) drama, e) crime shows, f) action shows, g) science fiction, h) horror shows, i) erotica (called "light blue" in Iceland), j) documentaries, k) music videos, 1) sport programs, $\mathrm{m}$ ) news, and $\mathrm{n}$ ) boxing.

Factor analysis (varimax rotation) revealed five factors when it came to the adolescents' viewing of television genres. The following genres loaded most heavily on the first factor, i.e. action programs, horror programs and boxing. This factor also included erotic programs, and was thus labeled the violence and erotica factor. It accounted for $20.7 \%$ of the variance and had an eigenvalue of 2.90 .

\section{Family Cohesion and Parental Supervision}

The 13 items that were used to measure family cohesiveness, i.e. the relationship between the adolescent and his/her parents, were borrowed and adapted from various scales, including a scale used by Rannsóknarstofnun uppeldis- og menntamála (RUM) in 1997 (The Institute for Educational Research in Iceland) and Cernkovich and Giordano (1987). 
It was expected that high scores on this Likert-scale would indicate a good family atmosphere and closeness between the subject and his/her parents, while low scores were indicators of emotional neglect.

The family cohesiveness question asked: "Answer the following statements to the best of your ability. Circle the answer that applies to you." In addition, the question specifically stated that the word "parents" also meant adoptive parents or stepparents. The scale ranged from 1 to 5,1 being never and 5 being frequently.

The following statements were included:

a) My parents ask my how I'm doing in school.

b) My parents are proud of me.

c) My parents trust me.

d) I have a good relationship with my parents.

e) My parents listen to my opinions and respect them.

f) I can talk to my parents about matters that bother me.

g) I can talk to my parents about everything.

h) I spend my free time with my parents.

i) I have the same interests as my parents.

j) My parents show me warmth and affection.

k) My parents help me with my homework.

1) It's easy for me to borrow money from my parents.

m)I show my parents that I care about them.

The seven items that made up the parental supervision Likert-scale are all commonly used to measure supervision and were presented in the same form as the statements which measured family cohesion. They have, for example, been used in one form or another by RUM, Haapasalo and Tremblay (1994) and Cernkovich and Giordano (1987).

It is crucial to get good measures of parental supervision since it has been found to be one of the strongest predictors of delinquent behavior (Loeber \& Stouthamer-Loeber, 1986). In addition, it is expected that parental supervision is negatively associated with viewing of television. Thus, lack of monitoring by parents may concurrently contribute to delinquent behavior among adolescents and their viewing of violent material. This would give some support to the theory of media delinquency that argues that watching violence is one of many manifestations of delinquency (Roe, 1995).

The following statements were included:

a) I obey rules about how long I can stay out.

b) My parents know whom I'm with when I'm not home.

c) My parents know whom I'm with when I go out in the evening.

d) My parents know my friends.

e) My parents know where my friends live.

f) My parents know how I'm doing in school.

g) I leave messages if my parents aren't home when I go out.

Originally it was expected that family cohesion, i.e. the adolescents' relationship with their parents, and parental supervision were two separate dimensions. However, although factor analysis revealed that they load separately on two factors, the reliability alpha for 
a combined scale of these items is .9256 and removing any one of them would lower the alpha. Hence, the measurement instrument appears to be quite reliable when all of the items are included in one scale, and it also appears that the family cohesion items and the supervision items are in fact to a large degree measuring the same concept. Also, the correlation between the cohesion items and the parental supervision items is .6426 ( $\mathrm{p}<$ $.001)$. This simply means that the better the relationship between the adolescents and their parents, the more likely the parents are to monitor their adolescents' behavior and their comings and goings. Or one could argue that this is actually the other way around, i.e. because parents supervise their adolescents, it may improve the relationship between the parents and their adolescents.

\section{Relationships with Siblings and Family Tension/Violence}

Patterson's coercive cycle of violence assumes that siblings provide a training ground for aggressive behavior (Patterson, 1986). Consequently, it is essential to measure the subject's relationship with his/her siblings. Frequent sibling fighting might also be manifested in increased tension and conflict in the home.

Thus, the sample was asked: "How often do you argue with your siblings (without physical fighting)?", "How often do you fight [physically] with your siblings?" And finally: "How often do you tease your siblings?"

The options were the following: doesn't apply because I'm the only child (coded as 1 - missing), never (2), infrequently (3), seldom (4), sometimes (5), often (6) and frequently (7).

To the best of the researcher's knowledge, no other study in Iceland had investigated the prevalence of child abuse, as reported by the children. The previously mentioned study by RUM asked the subjects how often in the past 12 months an adult they knew well had punched them, hit them, kicked them or headbutted them - without asking specifically about what relations that adult had with the child.

Two questions examined how often the subject had observed verbally and physically violent acts in his/her home, while another two questions asked specifically how often the students had been subjected to various violent behaviors by their parents - verbal and physical.

More specifically, "How often do you see someone at home scream or fight with someone else?" and "How often do you see someone at home use physical violence against someone else (kick, slap, punch, put in a headlock, headbut, burn [scorch], pull hair or push)?" "How often do your parents or your custodians scream at you or fight with you?" And finally: "How often do your parents or custodians use physical violence against you (kick, slap, punch, put in a headlock, headbut, burn [scorch], pull hair or push)?"

The adolescent could respond never (1), infrequently (2), seldom (3), sometimes (4), often (5) and frequently (6).

Since abuse doesn't necessarily happen on regular basis like once a day or once a week, leaving the interpretation of the options up to the adolescents was thought to be a better choice than using more specific options. The rationale for that was the same as for using the genre-viewing scale, i.e. if the adolescent feels that he is being abused frequently, even though it may be twice a year but not every day - that is what really counts. It's the adolescent's interpretation of the event and the impact of the event that matters, but not how often it occurs in terms of days or weeks. Another adolescent might consider twice a year to be seldom because that's what it feels like to him/her. 
It was originally expected that the items which measured family tension/violence might load on three separate factors (fights with siblings, observing violence and being the victim of violence), and they did, but the reliability alpha for the combined items on a single scale was .7385 and removing any item would have lowered it - made the scale less reliable as a measurement instrument.

\section{Aggression, Delinquency and Illicit Drug Use}

Most of the questions that measured aggression were used in the spring of 1997 by The Institute for Educational Research in Iceland (RUM).

The question on aggression asked: "In the past 12 months, how often have you done the following to another human being?" a) punched, b) pushed, c) kicked, d) slapped, e) put in a headlock, f) headbutted, g) burnt [scorched], h) pulled hair, i) threatened violence, and $\mathrm{j}$ ) threatened with a weapon.

The options were: never (coded as 1), once (2), 2-5 times (3), 6-9 times (4), 10-13 times (5), 14-17 times (6) and 18 or more times (7).

These 10 aggression items were combined into a single scale with a reliability alpha of .8813 .

A number of the items that made up the delinquency scale were borrowed from a 54item scale that Moffitt and Silva used in New Zealand (Moffitt \& Silva, 1988). In addition, quite a few items were new and were constructed after the researcher's conversation with Karl Steinar Valsson, a criminologist and an assistant police chief with the Reykjavík Police Department. Moffitt has argued that delinquency is normative during adolescence and that most people do something illegal during that period of their lives (Moffitt, 1993). By using a normative scale of delinquency, it is believed that one can get a greater range in behaviors.

Most of the 28 items that were included in this questionnaire are behaviors that are believed to be fairly common in Iceland. A few items on the New Zealand scale were either culturally specific to New Zealand, like stealing money from milk bottles or placing things on railway tracks, or they were simply so common in Iceland that they are not considered deviant at all (like going to R-rated movies or swearing loudly).

The questions on delinquncy asked: "In the past 12 months, how often have you done the following?" The answer choices and the coding was the same as for the aggression scale.

Some of the items (three of them), which measured drug use, are to be found on the original 29-item illegal scale used in New Zealand, while other items were added.

Again, the answer options were the same, and the coding was the same, as for the aggression scale.

The question on drug use asked: "In the last 12 months, how often have you..?" a) sniffed glue or other poisonous chemicals, b) used cannabis like hashish and/or marijuana, c) drunk alcohol to get intoxicated, d) used heroin, e) used pills to get high, f) used ecstasy (e-pills), g) used cocaine, h) used LSD, and i) used amphetamine.

Combining all of the juvenile delinquency items into a single scale, as RUM has done in the past, for example, was considered to be seriously problematic for various reasons. The first of them being that the items vary tremendously in their seriousness, from simply causing their victims annoyance, like the crank phone calls, to being serious felonies that carry several months in penitentiaries - breaking into homes to steal or stealing cars, for example. Instead of trying to come up with some arbitrary way of weighing each item in a combined scale of all of these items, varimax rotation was used to factor analyze them. 
During the first factor analysis attempt, six factors emerged. However, one of them didn't seem to have any theoretical explanation at all - so the factors were forced down to five, resulting in much cleaner factors.

The first factor accounted for $39.9 \%$ of the variance and had an eigenvalue of 14.78 . It included the 11 most serious offenses on the delinquency list, i.e. a) stolen a car, b) broken into cars to steal stereos or CDs, c) broken windows of school buildings, stores or other buildings, d) damaged a car by keying it or broken the mirrors, e) broken parking meters to steal money, f) broken into homes or companies to steal, g) fought in the streets, h) carried a weapon, knives or bats, for example, i) hurt someone seriously in a fight, j) used weapons in a fight, k) stolen something that was worth more than 5,000 Icelandic krónur. This factor was labeled serious crimes factor. In addition to the items mentioned above, blowing up home-made bombs had a secondary loading of $.47 \mathrm{on}$ it.

The second factor included six substance abuse items, i.e. a) used cocaine, b) used ecstasy, c) used heroin, d) used LSD, e) used pills, and f) used amphetamine. This factor had an eigenvalue of 3.85 and accounted for $10.4 \%$ of the variance. Since all of the hard drugs items loaded on this factor, it is labeled hard drugs factor. Interestingly, breaking into homes and companies was the only serious crimes item that also had a secondary loading on this factor (.49). One might have expected a stronger relationship between these two factors, considering that criminal behavior is in many cases the result of substance abuse as the drug addicts resort to crimes to finance their drug use. Nevertheless, the fact that breaking into homes loaded on this factor seems to indicate that those adolescents who use hard drugs are financing their substance abuse by breaking and entering.

The third factor had an eigenvalue of 2.59 and accounted for $7 \%$ of the variance. Almost all of the items which loaded on this factor were alcohol-related, i.e. a) bought alcohol, b) stolen alcohol from parents, c) taken money from parents or custodians without their permission, d) been truant, e) stolen something worth less than 5,000 Icelandic krónur., f) drank alcohol to get intoxicated, and g) used cannabis. Consequently, this factor was labeled as alcohol-related behavior.

It could be argued that most of these items are minor transgressions and for the most part normative during the years of adolescence. It's interesting to note that using cannabis loaded on this factor but not the drug factor. It's possible that these adolescents are, what has been termed, recreational users, i.e. they are once-in-a-while users of narcotics (Gunnlaugsson \& Thórisdóttir, 1999). Furtherore, it's quite likely that the those, who will later abuse drugs to a larger extent, haven't moved on to the harder drugs. Thus, at this stage in their lives, they are going through a transitional period, moving from just alcohol consumption to drugs, and using cannabis is the first step in that transition.

Stealing something worth more than 5,000 Icelandic krónur and stealing clothes from clothing stores had secondary loadings on this factor, i.e. they had loadings of .44 and .46 respectively.

The fourth factor accounted for $4.3 \%$ of the variance and had an eigenvalue of 1.60 . The common theme of many of the items that loaded on this factor was vandalism. The following items loaded on it: a) blown up home-made bombs, b) vandalized bus shelters, c) stolen something from convenience stores d) lit fires where it was forbidden, e) damaged school property, f) made crank phone calls, and g) written on walls or fences.

These acts appear to be very juvenile, i.e. something that the younger kids would do, like making crank phone calls and damaging school property. Again, quite a few of them can probably be considered normative, something that a large number of adolescents do. 
Five other items had secondary loadings on this vandalism factor, i.e. carried a weapon, fought in the streets, broke windows, and taken money from parents without their permission and stolen something worth less than $5000 \mathrm{kr}$.

The fifth and final factor included mostly behaviors that have to do with stealing something, i.e. a) stolen books from bookstores, b) stolen clothing (coats and other things) from school mates, c) stolen clothing from clothing stores, d) cheated on a test, and e) run away from home, and e) uses glue to get high. In addition, breaking parking meters and vandalizing bus shelters had secondary loadings on this factor. The eigenvalue for this stealing factor was 1.53 and it accounted for $4.1 \%$ of the variance.

As there was a problem with skewness in the distribution of the five delinquency factors, the factors were transformed into scales, which were later dichotomized and recoded. An average score of 1 on a scale was recoded as 0 (having never done any of the delinquent acts on the scale) and an average score of 1.01 or higher was coded as 1 (having trangsgressed). The five scales, or five types of behaviors, were then combined to produce a single delinquency score for each subject. Thus, the scores ranged from 0 for those who had never transgressed to 5 for those who were the most delinquent.

Looking at the frequency of the various behaviors, it is clear that it is quite common for adolescents to vandalize things, and considering how many adolescents engage in vandalism, it appears to be a normative behavior during adolescence; $82.7 \%$ or 550 adolescents had engaged in vandalism. Seven out of every 10 adolescents had engaged in alcohol-related behavior, close to $40 \%$ had committed at least one of the more serious crimes but only $2.7 \%$ (18 individuals) had used hard drugs.

It appears that adolescents move from one type of delinquent behavior to another type, or stage, of behavior. For example, vandalism seems to precede the alcohol-related behavior as only 48 subjects had engaged in alcohol-related behavior without having vandalized, while 120 subjects had vandalized without engaging in alcohol-related behavior, and 427 of 477 subjects who had engaged in alcohol-related behavior had also committed vandalism.

Alcohol-related behavior in turn seems to precede stealing as only 30 students had scores on the stealing scale without having used alcohol. On the other hand, 208 subjects had used alcohol without stealing and 265 of 297 who steal also use alcohol.

It is quite clear that most adolescents who steal have also vandalized as only 29 of those who had scores on the stealing scale had never vandalized while 279 subjects had vandalized without stealing and 267 subjects had scores on both scales.

Stealing, however, does not seem to be a necessary condition for committing the more serious crimes. Four out of 10 adolescents who had committed at least one of of the more serious crimes didn't have any scores on the stealing scale. These results appear to give some support to the idea of different pathways to delinquency, as stealing is a non-aggressive behavior while many of the items, which made up the serious crimes scale, measured aggressive behavior.

It is clear from the data that adolescents vandalize and engage in alcohol-related behavior before moving on to committing the more serious crimes. Only 11 subjects had committed serious crimes without vandalizing and only 28 subjects had committed serious crimes without engaging in alcohol-related behavior.

Sixteen out of the 18 individuals who had used hard drugs had also committed the more serious crimes, and they had all vandalized something and engaged in alcohol-related behavior, and all but one had a score on the stealing scale. 
Thus, the data appear to provide evidence for the claim that adolescents do indeed gradually add to their repertoire of delinquent behaviors, and that the most delinquent ones have sampled all five types of behaviors and consequently score on the highest on the delinquency scale.

It should be noted, of course, that there were 57 adolescents who had a perfectly clean slate, while 112 had engaged in just one type of delinquent behavior, 153 had engaged in two types of behaviors (mostly vandalism and alcohol-related behavior), $192 \mathrm{had}$ engaged in three types of behaviors (either vandalism, alcohol-related behavior and stealing, or vandalism, alcohol-related behavior and serious crimes), 125 had engaged in the four previusly mentioned behaviors, and 16 of the 18 hard-drug users had engaged in all five types of behaviors.

\section{Results}

\section{The Relationship Between Violence Viewing and Inter-Personal Aggression}

Taking into account the large number of studies that show a significant relationship between viewing of violence and aggressive behavior, it was hypothesized that there would be a positive relationship between the adolescents' score on the aggression scale and their viewing of violence.

Hypothesis 1 was supported. However, viewing of violence only explained $2 \%$ of the variance for the whole sample while gender seemed to explain $11 \%$, and more importantly, the family environment, both family tension/violence and family cohesion explained $17 \%$ of the variance (table 1). Thus, it can be concluded that yes, there is a relationship between watching violence on television and aggressive behavior. Nonetheless, other factors have much stronger influence on adolescents' aggression.

Table 1. The Relationship Between Adolescents' Viewing of TV Violence and Their Aggression

\begin{tabular}{|c|c|c|c|c|}
\hline & 1. & 2. & 3. & 4. \\
\hline $\begin{array}{l}\text { age } \\
\text { gender }\end{array}$ & $\begin{array}{l}, 01 \\
-, 33^{* * * *}\end{array}$ & $\begin{array}{l}, 01 \\
-, 33^{* * * *}\end{array}$ & $\begin{array}{l}-, 03 \\
-, 27^{* * * *}\end{array}$ & $\begin{array}{l}-, 04 \\
-, 20^{* * * *}\end{array}$ \\
\hline $\begin{array}{l}\text { neighbourhood education } \\
\text { neighbourhood income }\end{array}$ & & $\begin{array}{r}, 02 \\
-, 00\end{array}$ & $\begin{array}{l}, 01 \\
, 05\end{array}$ & $\begin{array}{l}, 03 \\
, 05\end{array}$ \\
\hline $\begin{array}{l}\text { family tension } \\
\text { family cohesion }\end{array}$ & & & $\begin{array}{l}, 25^{* * * *} \\
-, 25^{* * * *}\end{array}$ & $\begin{array}{r}, 24^{* * * *} \\
-, 23^{* * * *}\end{array}$ \\
\hline viewing of violence & & & & $18^{* * * *}$ \\
\hline $\begin{array}{l}\text { R square } \\
\text { Adjusted } R \text { square } \\
R \text { square change }\end{array}$ & $\begin{array}{l}, 11 \\
, 11 \\
, 11^{* \star * *}\end{array}$ & $\begin{array}{l}11 \\
, 10 \\
, 00\end{array}$ & $\begin{array}{l}, 28 \\
, 27 \\
, 17^{\star \star \star \star}\end{array}$ & $\begin{array}{l}, 31 \\
, 30 \\
, 02^{\star * \star *}\end{array}$ \\
\hline
\end{tabular}

$* \mathrm{p}<.05, * * \mathrm{p}<.01, * * * \mathrm{p}<.001, * * * * \mathrm{p}<.0001$

Once gender has been factored out, family cohesion and family tension/violence still explain $20 \%$ of the variance for both boys and girls (table 2). Since the zero-order correlations between family tension/violence and family cohesion and aggression are both significant, it seems that family cohesion and family tension/violence both contribute significantly to adolescents' aggressiveness. 
Table 2. The Relationship Between Girls' and Boys' Viewing of Violent Television Shows and Their Aggressiveness

\begin{tabular}{lcrrrrrrc} 
& \multicolumn{9}{c}{ girls } & \multicolumn{1}{c}{ boys } \\
& 1. & 2. & 3. & 4. & 1. & 2. & 3. & 4. \\
\hline age &, 07 &, 08 &, 04 &, 01 &,- 04 &,- 04 &,- 08 &,- 09 \\
n. education & &,- 05 &,- 06 &,- 03 & &, 08 &, 06 &, 08 \\
n. income & &,- 05 &, 01 &, 00 & &, 03 &, 07 &, 07 \\
family tension & & & $, 33^{* * * *}, 31^{* * * *}$ & & & $, 22^{* * *}, 20^{* *}$ \\
family cohesion & & &,$- 19^{* *}$ &,$- 16^{* *}$ & & &,$- 31^{* * * *}-, 30^{* * * *}$ \\
viewing of TV violence & & & &, $21^{* *}$ & & & &, $15^{* *}$ \\
R square &, 01 &, 01 &, 21 &, 26 &, 00 &, 01 &, 21 &, 23 \\
Adjusted R square &, 00 &, 00 &, 20 &, 24 &,- 00 &,- 00 &, 19 &, 21 \\
R square change &, 00 &, 01 & $, 20^{* * * *}, 04^{* * * *}$ &, 00 &, 01 & $, 20^{* * * *}, 02^{*}$ \\
\hline
\end{tabular}

$* \mathrm{p}<.05, * * \mathrm{p}<.01, * * * \mathrm{p}<.001, * * * * \mathrm{p}<.0001$

Nonetheless, viewing of television violence explains 4\% of girls' aggressiveness and $2 \%$ of boys' aggressiveness. This apparently greater influence of television violence on girls is consistent with previous findings by Eron et al. (1986). It may be, as Eron et al. have proposed, that because girls have traditionally been less aggressive than boys, there is more room for television to affect them. Their conclusion was as follows:

Even though boys in general obtain higher aggression scores than girls and watch significantly more violent $\mathrm{TV}$, the correlation between the two variables is now actually higher for girls than for boys, indicating they are now even more affected by TV violence than are boys (Eron \& Huesmann, 1986).

\section{The Relationship Between Violence Viewing and Juvenile Delinquency}

Hypothesis 2 stated that there would be a positive relationship between viewing of violence and delinquent behavior. This hypothesis was supported as viewing of television violence accounted for $6 \%$ of the variance for the sample as a whole (table 3 ).

Table 3. The Relationship Between Adolescents'Viewing of TV Violence and Their Delinquent Behavior

\begin{tabular}{|c|c|c|c|c|c|}
\hline & 1. & 2. & 3. & 4. & 5. \\
\hline $\begin{array}{l}\text { age } \\
\text { gender }\end{array}$ & 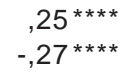 & $\begin{array}{l}, 25^{\star \star \star \star *} \\
-, 27^{\star \star \star \star *}\end{array}$ & $\begin{array}{r}, 20^{\star * \star *} \\
-, 18^{* * * *}\end{array}$ & 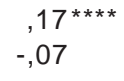 & 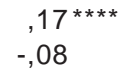 \\
\hline $\begin{array}{l}\text { n. education } \\
\text { n. income }\end{array}$ & & $\begin{array}{r}, 02 \\
-, 07\end{array}$ & $\begin{array}{r}, 01 \\
-, 02\end{array}$ & $\begin{array}{r}, 05 \\
-, 02\end{array}$ & $\begin{array}{r}, 04 \\
-, 02\end{array}$ \\
\hline $\begin{array}{l}\text { family tension } \\
\text { family cohesion }\end{array}$ & & & $\begin{array}{l}, 08 \\
-, 37^{\star * * *}\end{array}$ & $\begin{array}{l}, 06 \\
-, 34^{\star * * *}\end{array}$ & $\begin{array}{l}, 06 \\
-, 34^{* \star * *}\end{array}$ \\
\hline viewing of TV viol. & & & &, $27^{* * * *}$ &, $28^{* * * *}$ \\
\hline total TV view. & & & & &,- 04 \\
\hline R square &, 14 & , 15 &, 30 & ,35 &, 36 \\
\hline Adjusted $\mathrm{R}$ square & 14 & ,14 & ,29 & ,35 & ,35 \\
\hline $\mathrm{R}$ square change &, $14^{\star \star * *}$ &, 00 &, $15^{\star \star * *}$ &, $06^{* * * *}$ & ,00 \\
\hline
\end{tabular}

$* \mathrm{p}<.05, * * \mathrm{p}<.01, * * * \mathrm{p}<.001, * * * * \mathrm{p}<.0001$ 
Looking separately at boys and girls, it is clear that the relationship between violence viewing and delinquent behavior is significant for both genders. The relationship between viewing of television violence and delinquent behavior is slightly stronger for girls than boys. Television violence accounts for $7 \%$ of the variance for girls while it explains $4 \%$ of the variance for boys (table 4).

Table 4. The Relationship Between Girls' and Boys' Viewing of Violent Television Shows and Their Delinquent Behavior

\begin{tabular}{|c|c|c|c|c|c|c|c|c|c|c|}
\hline & & & girls & & & & & boys & & \\
\hline & 1. & 2. & 3. & 4. & 5. & 1. & 2. & 3. & 4. & 5. \\
\hline age &, $28^{* * * *}$ &, $27^{* * * *}$ & *, $21^{* * * *}$ & *, $17^{* * *}$ &, $17^{* * *}$ &, $25^{* * * *}$ & *, $25^{* * * *}$ & * 20 ** &, $19^{* *}$ &, $18^{* *}$ \\
\hline n. education & &,- 02 &,- 03 &, 01 &, 01 & &, 07 &, 07 &, 10 &, 10 \\
\hline n. income & &,$- 12^{*}$ &,$- 05-$ & ,06 &, 06 & &,- 02 &, 02 & ,02 & ,02 \\
\hline tension & & &, 09 &, 06 &, 06 & & & ,04 & ,03 & ,04 \\
\hline cohesion & & &,$- 41^{* \star \star *}$ & $\star-, 37^{* * * *}$ & ${ }^{*}, 37^{* * * *}$ & & &,$- 33^{* * * *}$ & $*-, 30^{* * * *}$ & ${ }^{*}-, 31^{* * * *}$ \\
\hline TV violence & & & &, $28^{* * * *}$ & ${ }^{*}, 29^{* * * *}$ & & & &, $22^{* * *}$ &, $23^{* * *}$ \\
\hline total TV view. & & & & &,- 04 & & & & &,- 04 \\
\hline $\mathrm{R}$ square & ,07 & ,09 & 29 & ,37 & ,37 &, 06 &, 07 & 18 & ,23 & ,23 \\
\hline Adjusted $R$ square & ,07 & ,08 & 28 & ,35 & ,35 &, 06 &, 06 & 17 & ,21 & ,21 \\
\hline$R$ square change &, $07^{* * * *}$ & ,02 &, $21^{* * * *}$ & ${ }^{\star}, 07^{\star \star \star \star \star}$ & *, 00 &, 06 &, 00 &, $11^{* * *}$ & *, $04^{\star \star *}$ &, 00 \\
\hline
\end{tabular}

$* \mathrm{p}<.05, * * \mathrm{p}<.01, * * * \mathrm{p}<.001, * * * * \mathrm{p}<.0001$

Interestingly, once viewing of television television was entered into the equation, the beta for gender became insignificant, making one want to make the claim that boys are more delinquent than girls simply because they watch more violence on television.

Total viewing of television was entered into the regression model after the viewing of violence but it did not explain a signifant percentage of the variance. Thus, it can be concluded that it is selective viewing of television violence, not total viewing of television, that is contributing to the adolescents' delinquency.

Age explained a significant proportion of the variance, both for girls and boys. It accounted for $6 \%$ of the variance for boys and $7 \%$ of the variance for girls as older adolescents are more delinquent than the younger ones (table 4). It may be proposed that it isn't age per se that is responsible for this, but rather everything that is associated with going through adolescence, i.e. increased time away from home and out of sight of parents, possibly increased influence of peers and along with that peer pressure.

Neither the percentage of college-educated people in the neighborhood, nor the average family income of the neighborhood did explain any of the variance for the sample as a whole or for boys. Before family tension/violence and family cohesion were entered into the equation, the beta for the average family income in the neighborhood turned out to be significant for girls.

Not surprisingly, and as might have been expected, family tension/violence and family cohesion together explained $15 \%$ of the variance for the total sample, $11 \%$ of the variance for boys, but $21 \%$ of the variance for girls.

When it was first entered into the equation, the beta for family tension/violence was significant at the $\mathrm{p}<.10$ level for the total sample but it was otherwise insignificant. Because of the strong correlation between family tension/violence and family cohesion, 
one has to be careful in making the assumption that it is lack of family cohesion alone that contributes to juvenile delinquency but not family cohesion in conjuntion with family tension/violence. The zero-order correlation beween delinquency and family tension/ violence is .23 while the zero-order correlation between family cohesion and delinquency is slightly stronger at -.47 .

Even though the family plays an important role in the delinquency of adolescents (the worse the family environment, the more delinquent the adolescents become), there is a clear indication that there is in fact a positive relationship between viewing of television violence and juvenile delinquency. The more delinquent adolescents watched the most violence. These findings are consistent with most other studies which have investigated the relationship between viewing of television violence and aggressive or antisocial behavior.

\section{Discussion}

If one looks first at interpersonal aggression, it is clear that one of the strongest predictors of aggressive behavior is gender.

After reviewing the literature on gender and aggression, Maccoby and Jacklin concluded that:

1. Males are more aggressive than females in all human societies for which evidence is available.

2. The sex differences are found early in life, at a time when there is no evidence that differential socialization pressures have been brought to bear by adults to "shape" aggression differently in the two sexes (Maccoby \& Jacklin, 1978: 242).

Thus, the findings from the present study are completely consistent with previous studies.

Secondly, family tension/violence and family cohesion are the strongest predictors of aggressive behavior among adolescents, accounting for one fifth of the variance. As numerous studies have shown, violence breeds violence and this is certainly the case. Lack of cohesion and high levels of family tension/violence make adolescents aggressive.

As hypothesized, the relationship between interpersonal aggression and the adolescents' viewing of television violence was significant, and family cohesion and tension are important as well.

Age alone accounted for a significant proportion of the variance when it came to juvenile delinquency. Age per se is hardly responsible for the behavior, but rather the changes that occur during adolescence - namely the increased importance of peers and the decreased time spent with the family. A study on American teenagers found that talking to their friends occupied more of their time than any other activity (Steinberg, 1993).

The importance of the peer group was clearly demonstrated in the study by RUM in 1997 when time spent with friends, peers' use of illegal drugs and their attitudes towards that use accounted for 59\% of the adolescents' use of illegal drugs and their smoking (Thórlindsson et al., 1998).

Unfortunately the present study did not include any peer measures, and thus the argument that age as a variable was at least partially measuring the influence of peers must be purely speculative.

More importantly, as was the case with interpersonal aggression, there is a significant relationship between viewing of violence and delinquency among Icelandic adolescents. But what does it mean? 
There are three possible answers to this question, i.e aggressive people prefer to watch violence, violence causes aggressive behavior, and finally, some third unknown variable is the cause of both. It is quite possible that all three of these choices have some merit and may even be correct.

A Canadian study by Black and Bevan found that aggressive people seek out aggressive material (Black \& Bevan, 1992). These findings could be explained in terms of Scarr and McCartney's genotype—>environment effect (Scarr \& McCartney, 1983). We tend to seek out environment that is consistent with our genotype. Thus, it's logical to draw the conclusion that aggressive individuals prefer aggressive material. As a child's genotype is related to his/her parents genotype, the parents of an aggressive child will provide him/her with an environment that is conducive to aggression. When it comes to television viewing, for example, it is quite possible that parents of aggressive children are equally likely to watch violence and even draw their children into their own viewing of violence. And thereby fostering an environment of aggression.

As Loeber and Stouthamer-Loeber have pointed out, causally related variables are often correlated with each other. Family factors, including genetic factors, that are believed to cause antisocial behaviors tend to be correlated with each other (Loeber \& Stouthamer-Loeber, 1986). Hence, the parent's genotype operates in conjunction with other parental and familial factors to increase the risk of antisocial behavior.

Along those lines, one can claim that a "bad" genotype only adds to the cumulative effects of bad parenting practices. It appears that "multiple-handicaps" are associated with higher probability of antisocial behavior among children (Loeber \& StouthamerLoeber, 1986).

On the other hand, television viewing may be the cause of aggressive behavior in relatively normal children, i.e. children without any major neuropsychological or behavioral problems. As the Bobo-doll studies by Bandura clearly demonstrated, children learn and imitate what they see when provided with the opportunity and if the behavior is not condemned (Bandura et al., 1963).

Thirdly, aggressive behavior/juvenile delinquency and viewing of violence may be a part of a certain lifestyle. In that case, viewing violence would not be the cause of the delinquency nor would the delinquent behavior be the cause of the violence viewing. Violence viewing could be but one part of a delinquent behavioral pattern. That argument is consistent with Roe's theory of media delinquency. Roe argued that adolescents' use of, what he preferred to call, socially disvalued media (watching violence and listening to hard rock/heavy metal music) is only one manifestation of delinquent behavior.

Even though this study was not designed to establish the directionality of the relationship between viewing of violence and aggression, the data do allow us to make some arguments about it.

The prsent study established that the family contributes significantly to adolescents' aggressiveness, accounting for one fifth of the variance. By controlling for the family environment when looking at the relationship between viewing of television violence and delinquency, one is indirectly, and at least partially, eliminating the possibility of aggression driving the viewing of violence.

To summarize, there is a significant relationship between viewing of television violence among Icelandic adolescents and their aggressive and delinquent behavior. Furthermore, it appears that the violence on television is the cause of the aggressiveness, rather than the agressiveness causing the viewing. 


\section{Bibliography}

Bandura A.; Ross, D. \& Ross, S. (1963) Imitation of Film-Mediated Aggressive Models, Journal of Abnormal and Social Psychology, 66(1): 3-11.

Bjarnason, Th. (1995) Administration Mode Bias in a School Survey on Alcohol, Tobacco and Illicit Drug Use, Addiction, 90: 555-559.

Black, S.L. \& Bevan, S. (1992) At the Movies with Buss and Durkee: A Natural Experiment on Film Violence, Aggressive behavior, 18, 37-45.

Bryant, J. (1989) Viewers' Enjoyment of Televised Sports Violence. In Wenner (Ed.). Media, Sports, and Society. Newbury Park, CA: Sage.

Cernkovich, S.A. \& Giordano, P.C. (1987) Family Relationships and Delinquency, Criminology, 25(2): 295321.

Eron, L. \& Huesmann, L.R. (1986) The Role of Television in the Development of Prosocial and Antisocial Behavior. In D. Olweus et al. (Eds.). Development of Antisocial and Prosocial Behavior: Research, Theories and Issues. Orlando, FL: Academic Press.

Gunnlaugsson, H. \& Thórisdóttir, R. (1999) Iceland and the Nordic Drug Survey: Drug Use, Public Attitudes and Youth. Young: Nordic Journal of Youth Research, 7(1): 19-35.

Gunter, B. (1983) Do Aggressive People Prefer Violent Television? Bulletin of the British Psychological Society, 36, 166-168.

Haapasalo, J. \& Trembley, R.E. (1994) Physically Aggressive Boys from Ages 6 to 12: Family Background, Parenting Behavior, and Prediction of Delinquency, Journal of Consulting and Clinical Pscyhology, 62(5): 1044-1052.

Huesmann, L.R. (1986) Psychological Processes Promoting the Relation Between Exposure to Media Violence and Aggressive Behavior by the Viewer. Journal of Social Issues, 42(3): 125-139.

Loeber, R. \& Stouthamer-Loeber, M. (1986) Family Factors as Correlates and Predictors of Juvenile Conduct Problems and Delinquency. In Tonry \& Morris (Eds.). Crime and Justice: An Annual Review of Research, 7, 29-149.

Maccoby, E.E. \& Jacklin, C.N. (1978) The Psychology of Sex Differences. Stanford, CA: Stanford University Press.

Moffitt, T.E. (1993) Adolescence-Limited and Life-Course-Persistent Antisocial Behavior: A Developmental Taxonomy, Psychological Review, 100(4): 674-701.

Moffitt, T.E. \& Silva, P.A. (1988) Self-Reported Delinquency: Results from an Instrument for New Zealand. Australian \& New Zealand Journal of Criminology, 21, 227-240.

Paik, H. \& Comstock, G. (1994) The Effects of Television Violence on Antisocial Behavior: A Meta-Analysis, Communication Research, 21(4): 516-546.

Patterson, G.R. (1986) The Contribution of Siblings to Training for Fighting: A Microsocial Analysis. In Olweus, Block \& Radker-Yarrow (Eds.). Development of Antisocial and Prosocial Behavior: Research, Theories and Issues. New York, NY: Academic Press.

Roe, K. (1995) Adolescents' Use of Socially Disvalued Media: Towards a Theory of Media Delinquency, Journal of Youth and Adolescence, 24(5): 617-631.

Scarr, S. \& McCartney, K. (1983) How People Make their Own Environments: A Theory of Genotype Environment Effects, Child Development, 54, 424-435.

Steinberg, L. (1993) Adolescence. New York, N.Y.: McGraw-Hill Inc., 1993.

Thórólfsson, Th.; Sigfúsdóttir, I.D.; Bernburg, J.G. \& Halldórsson, V. (1998) Vímuefnaneysla ungs fólks: Umhverfi og aðstæður. Reykjavík, Iceland: Rannsóknastofnun uppeldis- og menntamála. 